The systematic investigation of the 'stationary' ionised calcium lines in the spectra of hot stars which Dr. Plaskett carried out led to the first clear demonstration that the material responsible for these lines had no motion with respect to our system of stars. His earlier suggestion that it was originally discharged by the hot stars and came to rest some distance away from them probably needs modification in view of the evidence for Eddington's hypothesis that the matter is distributed throughout interstellar space, and indeed Dr. Plaskett, in a very recent paper, has himself given some of the strongest evidence for the latter view by showing, from the consideration of three separate groups of stars, that the average distance of the cloud is half that of the stars in the spectra of which its lines appear. It must be remembered also that Eddington's work in this connexion would not have been possible but for the thoroughness and accuracy of Plaskett's original investigation.

The idea that the galaxy is rotating is not a new one, but the evidence for some former ideas on this matter is now known to be spurious. The subject has lately come to the fore again through the realisation that our stellar system is probably a spiral nebula, and therefore is in all probability rotating in the manner which the appearance of those bodies forces us to admit. Specific evidence for the rotation recently came from Oort and Lindblad, and Dr. Plaskett at once perceived that his radial velocity measurements could throw an important light on the matter. He analysed the motions of the distant stars-those of types $B$ and $O$, of which he had made a special study - and was able to show that they gave clear indications of rotation about a centre in galactic longitude $324 \cdot 5^{\circ}$, which agrees with the position given by Oort and also with that found by Shapley for the centre of the galactic system from totally different considerations based on the distribution of globular clusters. The centre of the galaxy is near the junction of the constellations Sagittarius, Ophiuchus, and Scorpio, in a 'rift' between two branches which is probably caused by obscuring matter hiding from us what would otherwise be the brightest part of the Milky Way. Dr. Plaskett's contributions to the elucidation of this problem have been characterised by the solidity and thoroughness which he has shown throughout his career, and his results, however their interpretation may vary, are permanent.

Dr. Plaskett, who has been invited to give the George Darwin lecture of the Royal Astronomical Society, has chosen as his subject "The High Temperature Stars". The lecture will be delivered on May 9, and will contain some hitherto unpublished material on these important bodies.

\title{
River Flow Records in the Ness Basin, Scotland.
}

$\mathrm{T}^{\mathrm{o}}$ those interested for scientific and technical reasons in the availability of trustworthy data respecting river flow in Scotland, the appearance of two unostentatious pamphlets, ${ }^{1}$ or monographs, containing records during recent periods of the Rivers Garry and Moriston, both in the Ness Basin, Inverness-shire, will be welcome not merely for the records themselves and the information they afford at the moment, but also as indicating the inauguration of a series of observations which, if continued and extended over a period of years, cannot fail to be of considerable value when the time arrives for dealing with questions of river development.

Capt.W.N.McClean, at his own pains and expense, in conjunction with some voluntary helpers, has set on foot the systematic collection of hydrological data which no public or authoritative body in Scotland (or indeed in Great Britain) is empowered or disposed to undertake. It is true that the Scottish Meteorological Department in Edinburgh has shown itself helpful in certain directions, and that it receives rainfall returns and provides general supervision over their collection, but the brunt of river gauging work falls at present on the private investigator. "River Flow Records", the organisation of Capt. McClean and his fellow-workers, is therefore an undertaking in the public interest which is deserving of acknowledgment for its altruistic labours. The quarterly reports, which are on sale at a nominal figure, are distributed not only to all who have given facilities for, or assistance in, the taking of measurements, but also "to others who it is hoped will help in assuring continuous measurements of the water resources of the country".

The two rivers which form the subject of the monographs have equivalent catchment areas, but some appreciable variation in rainfall. The River Moriston has a catchment area above the gauging section of 149 square miles, and the River Garry an area of 148 square miles. For both rivers, therefore, a flow of 400 cusecs is equal to 0.1 inch per day on the catch-

I River Flow Records, Ness Basin : River Moriston and River Garry. Reports on River Flow, July to September $1929 . \quad$ Each 4 pp. +3 tables. (Parliament Mansions, Victoria Street, S.W.1.) 1s. 6d. each. ment area. The flow-off of the Garry, however, is considerably greater than that of Moriston on account of the larger area under heavy rainfall at the headwaters of the former. For the two months of August and September in the period under review the ratio was as much as 3 to 2 .

The comparison of flow-off and rainfall for the Moriston covers a period of a little more than nineweeks in the autumn of 1929 (July 27-Sept. 30) based on actual measurements of flow made between Sept. 13 and Sept. 26. These few measurements, Capt. McClean considers, are sufficient to enable a fair estimate to be made of the flow near Invermoriston from a moderately low river to a considerable flood, and permit of a rough prediction of flow for any recorded river height. In default of more extended observations, the figures in the tables undoubtedly will be helpful, but it is obvious that there is need to supplement and compare them with later readings over a longer period, in order to increase the range, to eliminate errors, and to secure closer approximations.

In the case of the Garry, measurements of flow were made between Aug. 27 and Sept. 11, 1929. Here, too, the records are for a very short period, but the author points to the observations which he kept of water level and rainfall during the three years 1913-15, the results of which were published in the Proceedings of the Institution of Water Engineers for 1927. The present records, therefore, are a resumption of the work previously carried on and unfortunately interrupted. It is of interest to note that the flow of the Garry does not change with the rapidity of that of the Moriston on account of the long narrow exit from Loch Garry. The loch rises gradually and has risen as much as 20 feet, storing at that level the equivalent of 3 inches of rainfall over its feeding area. As a consequence, floods below the loch are delayed and spread over a long period.

It is understood that not only are the present records to be continued, but also that similar readings and measurements are contemplated for other streams in the Ness Basin, including the Rivers Oich and Ness. BRysson CunNinghaM.

No. 3148, VoL. 125] 